\title{
Track and Trace Solution for Pharma Industry Using - Enterprise Application Integration Technology
}

\author{
${ }^{1}$ Mr Dubbudu Rama Krishna Reddy, ${ }^{2}$ Prof P. Premchand \\ ${ }^{I}$ Research Scholar, Rayalaseema University, Kurnool. Reg. Id: PP. COMP.SCI. 0264 \\ ${ }^{2}$ Professor \& Dean, Faculty of Informatics, Dept. of CSE, UCE, Osmania University.
}

\begin{abstract}
In today's competitive economic environment, track and trace (the capability to determine present and past locations of products through the whole supply chain) is becoming an increasingly urgent necessity and a key differentiator in many industries, enhancing pilferage reduction, counterfeit prevention and targeted recalls, and improving supply chain efficiency, synchronization, visibility, and security. The proposed solution helps all major drug manufacture companies to prevent counterfeit drugs, effective supply chain management and to find better marketing strategies to project the products and also to help the end consumers to get the right drugs for right diseases. The solution not only feasible in economically but also helpful socially to protect the patients to get proper medicine to cure the problems and prevent anti social elements. The research goal is to provide a solution to uniquely identify a drug in supply chain management and to prevent counterfeit drugs that prevents consumer from taking fake drugs. The proposed solution provides how to identify uniquely a drug across the supply chain with serial number generation, assignment and implement Track and Trace (T\&T) solution as per the norms with electronic product code (EPC)/GS1 standards (http://www.epcglobalinc.org/home/).
\end{abstract}

Keywords: Track and Trace, Serialization, Anti counterfeiting, Pharmaceutical Industry

\section{Need and Importance of Research Problem}

The existence and dissemination of counterfeited medicines was first addressed, at an international level, back in 1985 at the Conference of Experts on the Rational Use of Drugs in Nairobi[5]. This conference resulted in the suggestion that the World Health Organization (WHO), alongside with other international nongovernmental agencies, should assess the feasibility of creating an organism that would collect data and inform governments about the nature and extend of counterfeiting.

Then, in 1992 WHO organized the first international meeting on counterfeit medicines in Geneva with the participation of great number of highly prestigious institutions (Interpol, World Customs Organization , International Narcotics Control Board, International Federation of Pharmaceutical Manufacturers and Associations, International Organization of Consumer Unions, and the International Pharmaceutical Federation), being most important outcome the definition of counterfeit medicine: "is one which is deliberately and fraudulently mislabeled with respect to identity and/or source. Counterfeiting can apply to both branded and generic products and counterfeit products may include products with the correct ingredients or with the wrong ingredients, without active ingredients, with insufficient (inadequate quantities of) active ingredient(s) or with fake packaging. Given the unfortunate, but expected, success of the counterfeit drugs market, in 1994, the WHO adopted the resolution WHA47.13 which requested the Director-General of WHO to assist Member States in their efforts to ensure that available medicines were of good quality, and in combating the use of counterfeit drugs. The need for greater international cooperation in combating counterfeit medical products has been reiterated through resolutions WHA52.19 (1999), WHA57.14 (2004) as well as the "Guidelines for the Development of Measures to Combat Counterfeit Drugs" (1999). From 1994 to 2004 many ICDRAs (International Conferences of Drug Regulatory Authorities) request WHO to assist Member States to adopt measures to combat counterfeit medicines circulating and, in Madrid (2004), ICDRA requested WHO to work on a draft international convention on counterfeit medicines.

Nevertheless up until 2006 the member states wouldn't reach an agreement on an international convention on counterfeit medicines. In February 2006 at the Rome conference, it was recommended that an international taskforce should be established. This action culminated in the creation of the International Medical Products Anti-counterfeiting Taskforce (IMPACT). This taskforce "is a voluntary grouping of governments, organizations, institutions, agencies and associations from developing and developed countries aimed at sharing expertise, identifying problems, seeking solutions, coordinating activities and working towards the common goal of fighting counterfeit medical products. IMPACT aims at ensuring appropriate regional representation, including in particular from developing countries. 
In 2007 at the IMPACT general meeting in Lisbon, a new document was endorsed: "Principles and Elements for National Legislation against Counterfeit Medical Products". This document focused on the public and personal health implications in relation to counterfeit medical products that need to be appropriately addressed in legislation. In 2008, a group of specialists of the boards of Pharmaceutical Industries contributed to the further development of previous document, proposing through a new document, some modifications to the directive 2001/83/EC that establishes the community code in relation to the medicines of human use.

This new document was presented to public consultation and more than 100 European institutions gave their say and proposed modifications. No opinions were disregarded and the document was transformed into a formal proposal for modification of the directive 2001/83/EC.

In 2009, a setback was seen, when the European Social and Economic Committee issued its formal opinion where it was expressed that the actions expressed themselves in the document weren't enough. It should also be taken into account the legal consequences for counterfeiting acts, the protection of intellectual property, customs monitoring and international cooperation. Later, it was realized that the problem of identification and traceability of the medicines was underestimated and some measures were proposed to avoid any legal/regulatory gaps on this subject. Interestingly enough, one of the driving forces that lead to the creation of IMPACT was the increasing international trade of pharmaceuticals and sales via the internet had, and have, further facilitated the entry of counterfeit products into the supply chain. This concern was also expressed later in 2009, by several Health Ministers of Countries belonging to the EU during the Employment, Social Policy, Health and Social Affairs Council. It was suggested that some measures had to taken in relation to the control of the origin and route of the raw materials used in the manufacture of medicines because frequently the raw materials are imported from outside the EU thus representing and additional threat to the quality and safety of the marketed medicines. All these entities collaborated on further changing this new document, that would change the directive 2001/83/EC, and finally in 2011 the European Parliament adopts the new legislation, that now should be transposed to the National Law of each member state.

\section{DIRECTIVE 2011/62/EU OF THE EUROPEAN PARLIAMENT AND OF THE COUNCIL of 8 June 2011.}

This new directive is an amendment to the Directive 2001/83/EC, on the Community code relating to medicinal products for human use, as regards the prevention of the entry into the legal supply chain of falsified medicinal products. It comes into play due to, as previously explained, "an alarming increase of medicinal products detected in the Union which are falsified in relation to their identity, history or source.

Those products usually contain sub-standard or falsified ingredients, or no ingredients or ingredients, including active substances, in the wrong dosage thus posing an important threat to public health".

There are 5 main topics addressed in this new directive:

- Unique identity (serialization): technology choice and implementation;

- Governance of the system: deciding who sees what data and on what terms;

- Modalities of verification: deciding how packs will be verified and what level(s) of authentication feature(s) will be required;

- White list and blacklist criteria: determining which prescription drugs are excluded from key requirements (deemed safe) and which non-prescription drugs are included (deemed risky);

- Mechanism of notification: of white listing and blacklisting.

- Globally, the frequency of fraudulent trade in pharmaceutical products is on the increase (reimbursement, counterfeiting, tampering, expired product).

- A number of governments such as Italy, Belgium, European countries have responded to this threat and have put mass-serialisation based counter-measures in place. Others are working towards similar approaches,

- $\quad$ FDA [1] (Food and Drug Administration) and a number of individual states in the US, which are pushing for RFID, based product tracking through electronic pedigrees.

- Many drug manufacturers are working in close collaboration with national agencies and have implemented tactical solutions where necessary to meet local mandates, to ensure patient safety and to protect the integrity of its business. Through EFPIA, PhRMA and EPCglobal, All manufactures are working in collaboration with other manufacturers, wholesalers and retailers to develop solutions for a safe and secure supply chain.

- The pharmaceuticals industry has struggled to ensure the integrity of its products as they are transferred between the different stops on the value chain from contract manufacturers to wholesalers to dispensers and finally to the patient. This is particularly true as products move across international borders. And the problem has been growing. More money is lost to counterfeiting with each passing year. Product theft is also on the rise - Freight Watch International has released statistics suggesting that drugs account for 
approximately $15 \%$ of the estimated US\$8 billion to US\$12 billion of annual cargo theft, which amounts to well over US\$1 billion annually.

- Preventing theft and counterfeiting have therefore become a key industry focus. Early approaches included tamper-proof packaging and 3-D holograms, but these are now considered too easy to manipulate, so these methods are no longer considered sufficient. Today, regulations include assigning a unique identification number to the smallest unit of sale (for example, a bottle) and tracking that product [5].

\section{Need and Importance of Research Problem}

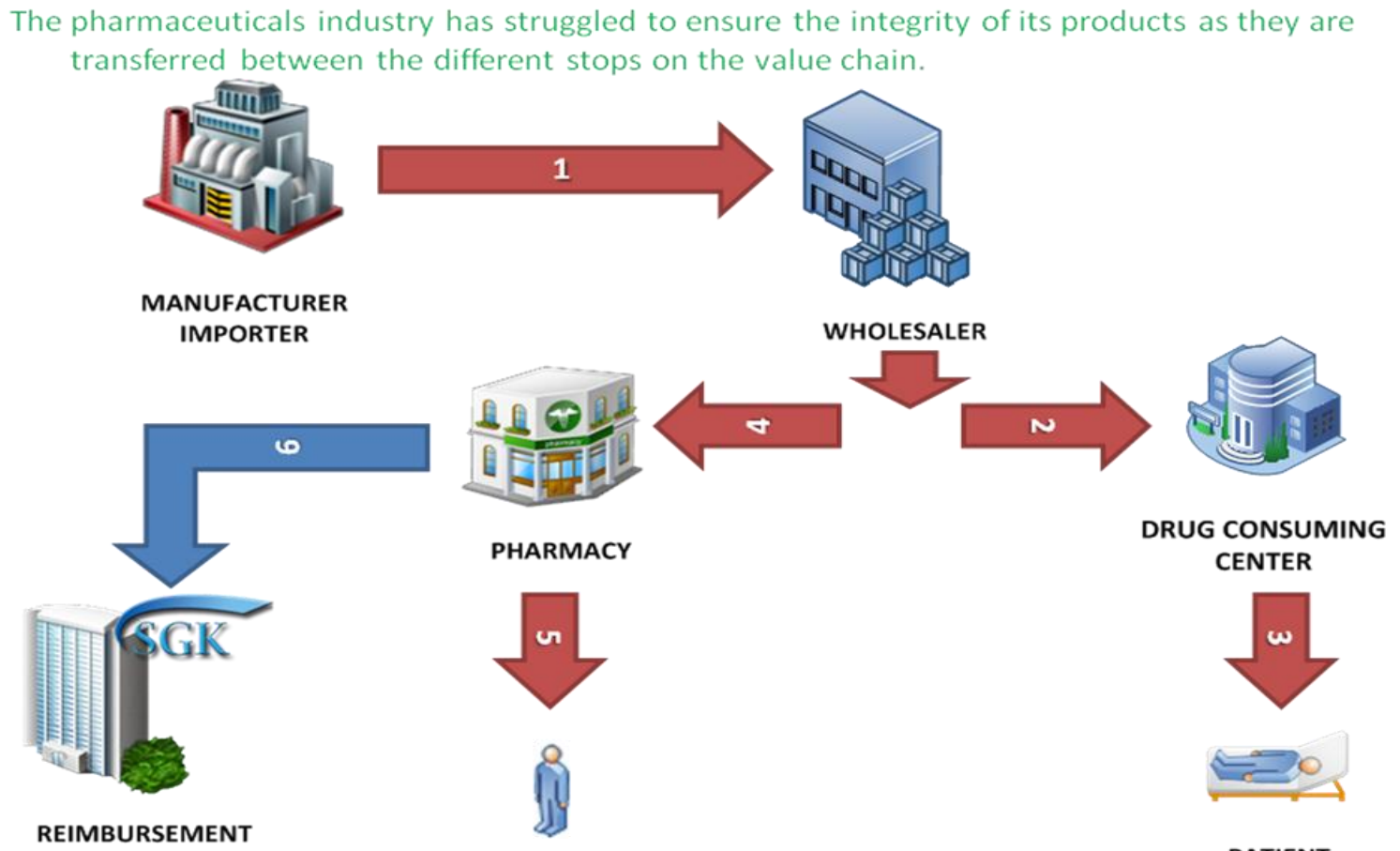

COMPANY OR

PATIENT ASSOCIATION

- More money is lost to counterfeiting with each passing year. Product theft is also on the rise

- Preventing theft and counterfeiting have therefore become a key Research Area.

- Early approaches included tamper-proof packaging and 3-D holograms (easily manipulated these days), so these methods are no longer considered sufficient.

- Today, regulations include assigning a unique identification number to the smallest unit of sale (for example, a bottle) and tracking that product.

\section{Enterprise Application Integration}

\section{Introduction}

According to Linthicum (2000) [4] EAI is the unrestricted sharing of data and business processes among any connected applications or data structures. Specifically EAI is the integration of internal systems within the enterprise (Microsoft, "Applying Microsoft Patterns to Solve EAI Problems", 2005). This means that every application that is, in one way or another, connected with other systems is in a sense a part of the EAI. The main purpose of this is to supply the entire organization with valid information, which is important for the organization to live up to the expectations of the market. 


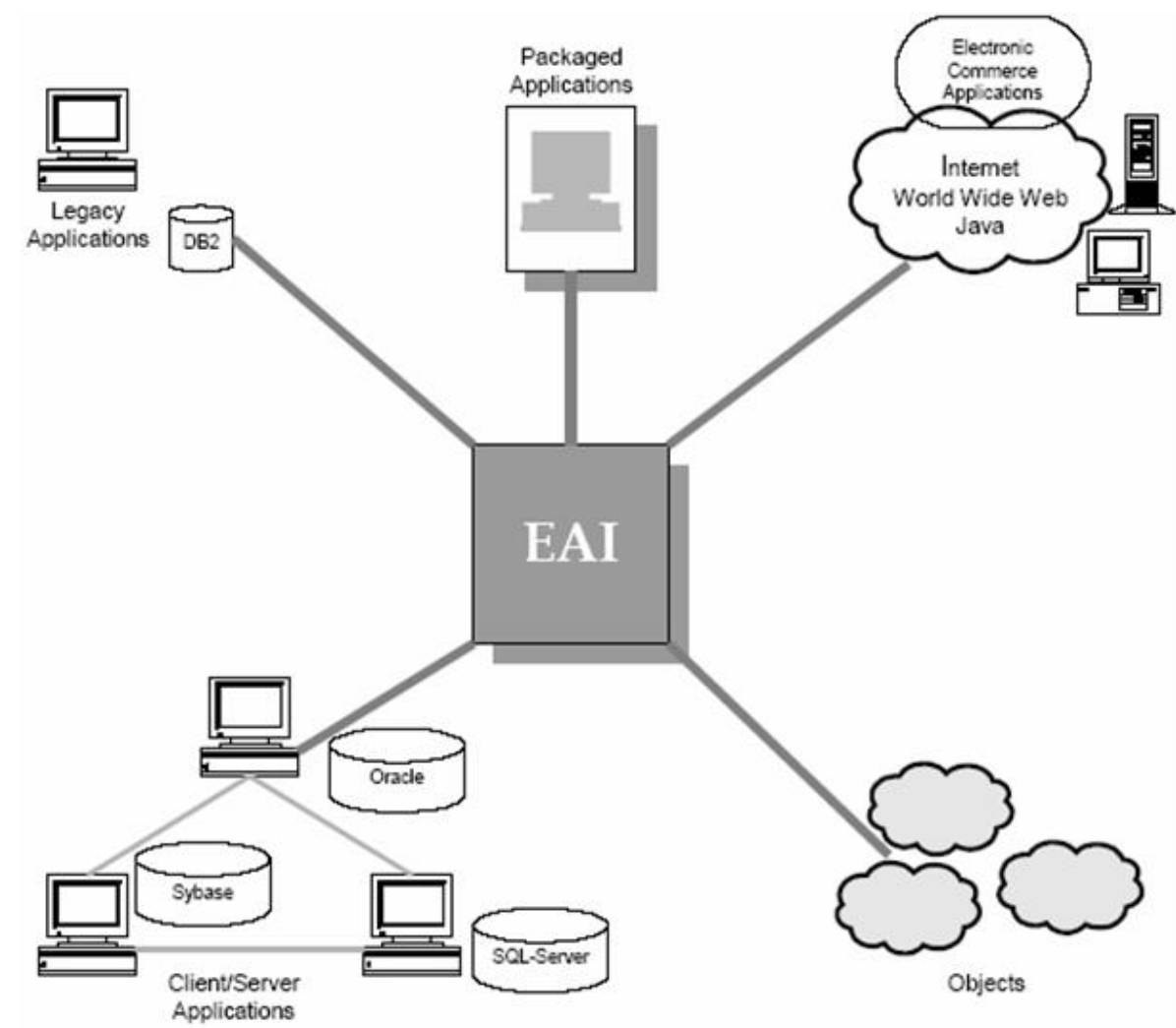

Figure An example of EAI within an organization (Linthicum, 2000)

The organizations of today must be able to handle changes in the customer requirements, harder competition from other suppliers and an increase innovation speed both within production and IT (Johannesson \& Perjons, 2001). It is the companies that makes the fastest decision and are able to deal with the modern way of thinking that will get an advantage towards their competitors. With this in mind there is an increased need for integrating the system within an organization. According to Johannesson \& Perjons (2001) the different information systems used to be tightly connected to a specific department, but now the knots are getting untied and the integration is increasing.

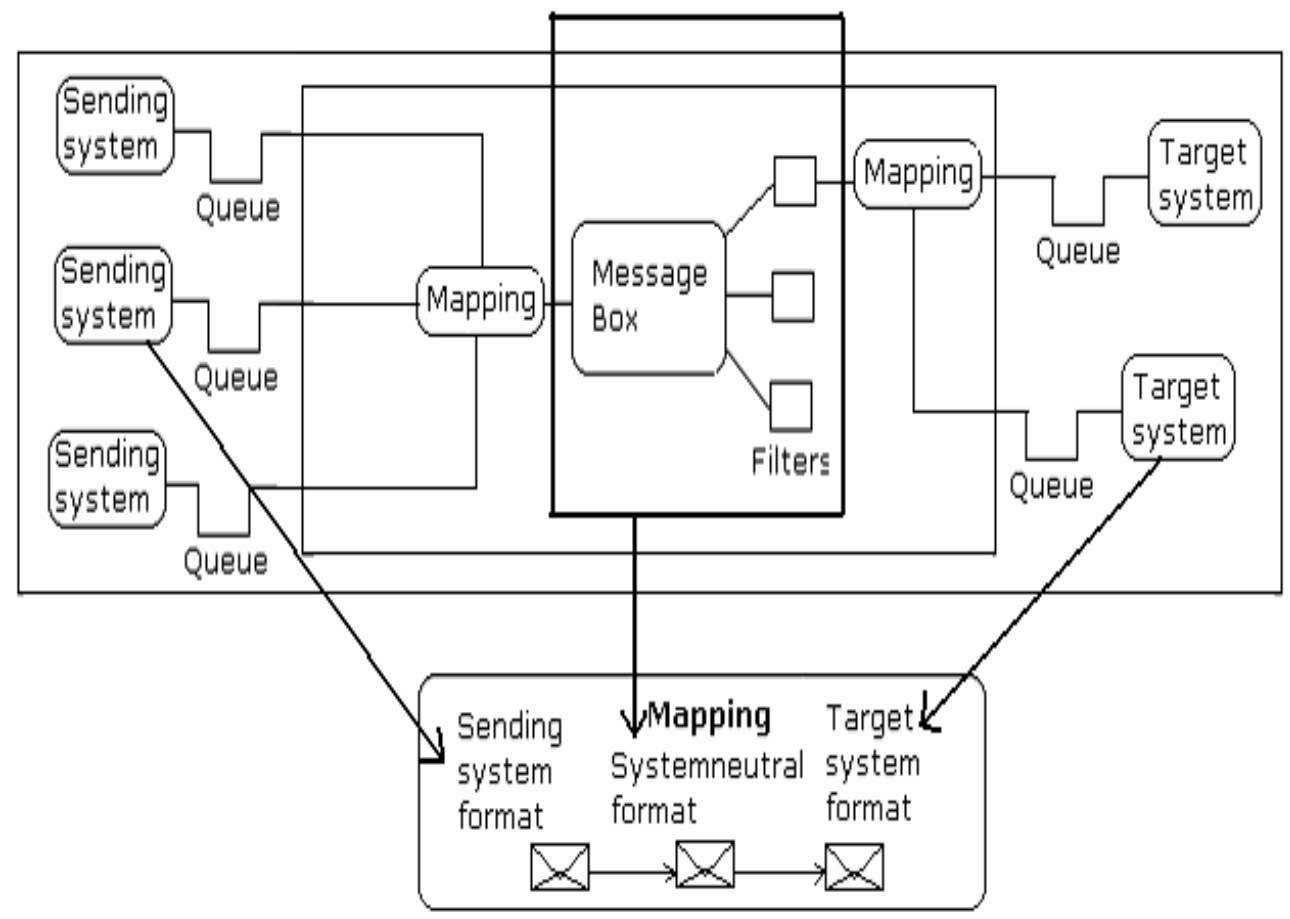


What happens is that the message format transforms to a common format. Before entering the integration platform the messages is being queued. As the platform is ready to pick up the message it maps it into its own format, the system neutral format and put the message in a message box to await further pick up. In the bold lined square the message is system neutral and could be filtered and enriched if necessary. It is now up to the target system to call on the 24 message and before it leaves the platform it will be transformed into the targets systems own format (Kristian Tomeby Imano, interview 15/4 2005). The last step is to put the message in a queue for the target system to pick it up.

\section{- Example EDIFACT $\rightarrow$ XML $\rightarrow$ Inhouse format}

1. The messages are queued before entering the integration platform .

2. The message format transforms to a common format. (Ex: XML)

3. As the platform is ready to pick up the message it maps it into its own format.

4. The last step is to put the message in a queue for the target system to pick it up.

\section{III. Methodology}

1. The proposal is to provide core functionality for integrating with the drug and providing a simple mechanism for authorization. Facilitating for backend externalisation with 3rd party Manufacturing/packing facilities.

Note: The solution will be integrating with backend using single interface, drug data can be received in XML, CSV formats with multiple versions supported. The Meta data for Finished Packs will be retrieved from backend systems and will presented in the Life cycle and Authentication views

2. The functionality to provide authorization functionality for internal and external pack authorization. Include internal and external event integration

3. Providing functionality for supply chain functionality (pedigree and track and trace).

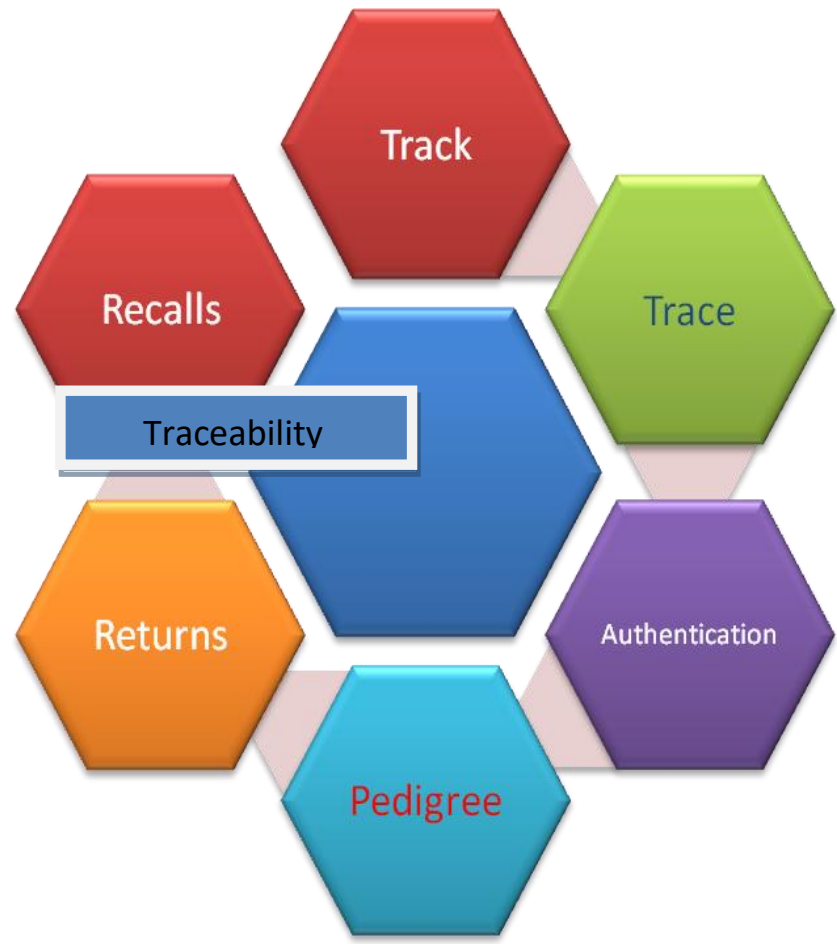

\section{Conclusion}

The research will identify the potential problems in identifying a drug uniquely and the objective is to provide a solution with serial number generation and assignment. The solution not only discusses individually about a drug but also identifies all manufacturers across industry with unique number by its site and location with unique number and the solution is as per norms with EPCIS. The dataset will be taken from drug manufacturing company; the XML files will be created based on data collected; the XML files will be taken as input to test this research proposal. 


\section{References}

[1]. "FDA 2006 Compliance Policy Guide for the Prescription Drug Marketing Act". http://www.fda.gov/OHRMS/DOCKETS/98fr/069211.htm.

[2]. IDC Home: The Premier Global Market Intelligence Firm. 11 February 2009. <http://idc.com/>.

[3]. "Counterfeit Drugs and Travel." 10 February 2009. <http://wwwn.cdc.gov/travel/contentCounterfeitDrugs.aspx >.

[4]. Linthicum, David S, (2000). Enterprise Application Integration, Addison-Wesley.

[5]. "Counterfeit Drug.” Wikipedia 10 February 2009. <http://en.wikipedia.org/wiki/Counterfeit_drug >.

[6]. "Epedigree.” Wikipedia 10 February 2009. <http://en.wikipedia.org/wiki/Electronic_pedigree>.

[7]. "IBM-A Smarter Planet.” 10 February 2009. <www.ibm.com/ibm/ideasfromibm/us/smartplanet/20081106/index2.shtml 